\title{
Uma reflexão acerca da formação laboratorial em rádio e a perspectiva das novas DCNs para o curso de Jornalismo
}

\section{A reflection on laboratorial training in radio, and the perspective of the new DCNs for Journalism major}

\section{Una reflexión acerca de la formación con laboratorio de radio y la perspectiva de las nuevas DCNs para el curso de Periodismo}

Ricardo Pavan ${ }^{1}$

Gabriela Starneck Lopes de Araújo ${ }^{1}$

DOI: http://dx.doi.org/10.20435/serie-estudos.v20i52.1244

\begin{abstract}
Resumo: As novas Diretrizes Curriculares Nacionais (DCNs) para o Curso de Jornalismo, instituídas em 2013, trazem uma preocupação singular com a prática laboratorial no ensino de Jornalismo conjugada com a construção de um pensamento teórico crítico e transformador no âmbito das Ciências Humanas e Sociais. Presumem a formação de um profissional apto a enfrentar o mercado em mutação e um cotidiano marcado por conflitos sociais. Apoiando-se na perspectiva de alguns pensadores da área, como Del Bianco (2014) Kishinevsky (2014), Meditsch (2001) e Spenthof (1998, 2005), o objetivo do artigo é debater as possibilidades dessas experimentações por parte de estudantes de Jornalismo com públicos reais em laboratórios específicos de emissoras de rádio pública e de caráter educativo-cultural. As práticas orientadas nesses espaços se mostram profícuas na formação de um jornalista mais comprometido com a ética cidadã e o contexto social em que se encontra inserido. Ao mesmo tempo, tornam-se um significativo dispositivo pedagógico para as escolas de Jornalismo desenvolverem no campo empírico as teorias problematizadas em outros componentes curriculares.
\end{abstract}

Palavras-chave: Diretrizes Curriculares Nacionais; formação laboratorial; jornalismo laboratorial.

Abstract: The new National Curriculum Guidelines (Diretrizes Curriculares Nacionais [DCNs]) of Journalism, signed in 2013, bring forth a unique preoccupation with laboratory practice in the teaching of journalism along with the building of a theoretical critical and transforming thinking in the humanities and social sciences. The guidelines consider the training of a professional in the

\footnotetext{
${ }^{1}$ Universidade Federal de Goiás (UFG), Goiânia, Goiás, Brasil.
} 
area able to deal with a changing market, and a day-to-day life marked by social conflicts. Based on some authors, such as Del Bianco (2014), Kishinevsky (2014), Meditsch (2001), and Spenthof $(1998,2005)$, this paper seeks to discuss some possibilities of such experimentations by students of journalism in specific public and educational-cultural radio station laboratories. Practices directed in this environment are meaningful for the training of journalists more involved in civic ethics and in the social context where they live. At the same time, they become a significant pedagogical device for schools of journalism to develop empirically theories problematized in other curriculum components of this course.

Keywords: National Curriculum Guidelines; laboratory training; laboratory journalism.

Resumen: Las nuevas Directrices Curriculares Nacionales (DCNs) para el Curso de Periodismo, instituidas en 2013, traen una preocupación singular con la práctica de laboratorio en la enseñanza de periodismo conjugada con la construcción de un pensamiento teórico, crítico y transformador en el ámbito de las ciencias humanas y sociales. Presumen la formación de un profesional apto a enfrentar el mercado en cambio y un cotidiano marcado por conflictos sociales. Apoyándose en la perspectiva de algunos pensadores del área, como Del Bianco (2014) Kishinevsky (2014), Meditsch (2001) y Spenthof $(1998,2005)$, el presente artículo busca debatir las posibilidades de esas experimentaciones por parte de estudiantes del Curso de Periodismo con públicos reales en laboratorios específicos de emisoras de radio pública y de carácter educativo-cultural. Las prácticas orientadas en esos espacios se muestran provechosas en la formación de un periodista más comprometido con la ética ciudadana y con el contexto social en que se encuentra inserido. Al mismo tiempo, se vuelven un significativo dispositivo pedagógico para las escuelas de periodismo desarrollaren en el campo empírico las teorías problematizadas en otros componentes curriculares del curso.

Palabras clave: Directrices Curriculares Nacionales; formación de laboratório; periodismo de laboratorio.

\section{AS MUDANÇAS PROPOSTAS PELAS DCNS AO CURSO DE JORNALISMO}

Foi pensando na interferência da era digital na comunicação que, em 2009, o então Ministro da Educação Fernando Haddad deu à Comissão de Especialistas nomeada pela Portaria MEC-SESU 203/2009 a tarefa de repensar o ensino de Jornalismo no contexto de uma sociedade em processo de transformação. "Trata-se de fenômeno decorrente do fortalecimento da democracia, no qual o Jornalismo, assim como outras áreas do conhecimento, desempenha papel decisivo, informando os cidadãos e formando as correntes de opinião pública" (BRASIL, 2013, p. 1).

A partir desse cenário, foram instituídas, em 2013, as novas Diretrizes Curriculares Nacionais para o Curso de Jornalismo (BRASIL, 2013). Entre as recomendações, a de que as instituições de ensino ofereçam aos estudantes, desde o primeiro semestre, atividades laboratoriais para promover a integração teoria/ prática no ensino do Jornalismo. 
Uma reflexão acerca da formação laboratorial em rádio e a perspectiva das novas DCNs para o curso de Jornalismo

Em 2013, o Ministério da Educação homologou as novas Diretrizes Curriculares Nacionais para o Curso de Jornalismo. A Comissão, responsável pela missão de discutir o ensino do Jornalismo, foi formada por profissionais de renome, como o professor e presidente José Marques de Melo, além de Alfredo Vizeu, Carlos Chaparro, Eduardo Meditsch, Luiz Gonzaga Motta, Lucia Araújo, Sergio Mattos e Sonia Virginia Moreira.

A proposta das Diretrizes Curriculares para o Curso de Jornalismo está dividida em seis critérios: Organização do Curso, Projeto Pedagógico, Perfil do Formando/do Egresso, Competências, Conteúdos Curriculares, Acompanhamento e Avaliação - sendo que cada item apresenta suas subdivisões.

O Projeto Pedagógico do Curso de Jornalismo deve observar nove indicati$v{ }^{2}$. O primeiro deles diz: "Ter por objetivo a formação de profissionais dotados de competência teórica, técnica, tecnológica, ética, estética para atuar criticamente

2 a) Ter por objetivo a formação de profissionais dotados de competência teórica, técnica, tecnológica, ética, estética para atuar criticamente na profissão, de modo responsável, contribuindo para o seu aprimoramento.

b) Dar ênfase ao espírito empreendedor e ao domínio científico que gerem pesquisas ao conceber, executar e avaliar projetos inovadores capazes de dar conta das exigências contemporâneas e de ampliar a atuação profissional a novos campos, projetando a função social da profissão em contextos ainda não delineados no presente.

c) Estar focado teórica e tecnicamente na especificidade do jornalismo, com grande atenção à prática profissional, dentro de padrões internacionalmente reconhecidos, comprometidos com a liberdade de expressão, o direito à informação, a dignidade do seu exercício e o interesse público; d) Aprofundar o compromisso com a profissão e os seus valores, por meio da elevação da auto-estima profissional, dando ênfase à formação do jornalista enquanto intelectual, produtor e/ ou articulador de informações e conhecimentos sobre a atualidade, em todos os seus aspectos; e) Cuidar da preparação de profissionais para atuar num contexto de mutação tecnológica constante no qual, além de dominar as técnicas e as ferramentas contemporâneas, é preciso conhecer os seus princípios para transformá-las na medida das exigências do presente;

f) Ter como horizonte profissional o ambiente regido pela convergência tecnológica, onde o impresso não seja a espinha dorsal do espaço de trabalho nem dite as referências da profissão, embora conserve a sua importância no conjunto midiático;

g) Incluir na formação as rotinas de trabalho do jornalista em assessoria a instituições de todos os tipos;

h) Atentar à necessidade de preparar profissionais que possam exercer dignamente a atividade como autônomos em um espaço cuja oferta de emprego não cresce na mesma proporção que a oferta de mão de obra;

i) Pensar a graduação como uma etapa de formação profissional continuada e permanente. (BRASIL, 2013, p. 2) 
na profissão, de modo responsável, contribuindo para o seu aprimoramento" (BRASIL, 2013, p. 2). No que consiste aos Conteúdos Curriculares, as novas DCNs propõem que o projeto pedagógico deve atender seis eixos de formação ${ }^{3}$, um deles relacionado à aplicação processual.

V - Eixo de aplicação processual, que tem por objetivo proporcionar ao jornalista ferramentas técnicas e metodológicas, garantindo coberturas em diferentes suportes: jornalismo impresso, radiojornalismo, telejornalismo, webjornalismo, assessorias de imprensa e outras demandas do mercado de trabalho. (BRASIL, 2013, p. 5).

Nota-se que esse eixo contempla a cobertura jornalística no radiojornalismo. Isso ocorre porque, assim como consta nas novas Diretrizes Curriculares, "a banda larga aumentou ainda mais o poder da notícia, com a possibilidade de emissões interativas entre todos os mecanismos difusores - rádio, TV, jornal, revista e quantos mais aparecerem, na síntese chamada Internet" (BRASIL, 2013, p. 6).

Nesse contexto, o ensino do radiojornalismo tem se mostrado significativo para a formação dos futuros profissionais jornalistas, tendo em vista que foi a linguagem desse veículo que influenciou o surgimento de outras mídias. Além disso, a teoria e a prática da linguagem radiofônica contribuem para que os estudantes também tenham um domínio maior sobre outras áreas do jornalismo.

O ensino da disciplina não prepara apenas para trabalhar no veículo rádio: quem sai dominando a linguagem do veículo se adapta muito mais facilmente tanto à expressão audiovisual quanto ao texto utilizado na internet. E os grandes sites de notícias estão copiando das redações de radiojornalismo o seu modo de produção- desde o serviço de radioescuta até a edição em fluxo contínuo- porque ninguém como o rádio tinha antes o know-how de trabalhar com informação jornalística em tempo real (MEDITSCH, 2001, p. 2).

O autor considera que é necessário que os estudantes de jornalismo saiam da graduação dominando todas as linguagens utilizadas para a veiculação de notícias. Apesar das dificuldades que vêm enfrentando, a mídia radiofônica continua sendo uma das mais acessíveis para o público. E isso se intensifica com o advento da internet, já que a tecnologia em rede permite a transmissão de som, ao vivo

3 I- Eixo de fundamentação humanística; II- Eixo de fundamentação específica; III- Eixo de fundamentação contextual; IV- Eixo de formação profissional; V- Eixo de aplicação processual; VI- Eixo de prática laboratorial. (BRASIL, 2013, p. 5) 
Uma reflexão acerca da formação laboratorial em rádio e a perspectiva das novas DCNs para o curso de Jornalismo

ou gravado, a baixíssimo custo, para qualquer parte do mundo (MEDITSCH, 2001). "O rádio na internet é uma das marcas da era da informação e de uma sociedade em rede que estão, definitivamente, entranhadas no nosso cotidiano" (CAMPELO, 2014, p. 68).

\section{A SUPERAÇÃO DA DICOTOMIA ENTRE TEORIA E PRÁTICA}

A divisão entre o ensino teórico e prático, quando se trata do ensino do Jornalismo, é uma antiga discussão. Até porque, quando o curso surgiu no Brasil (FEDERAÇÃO NACIONAL DOS JORNALISTAS [FENAJ], 2017), "havia uma série de deficiências técnicas, como falta de equipamentos, o que também contribuiu para uma configuração mais humanística" (MARTINS, 2012, p. 85).

Mesmo com a aquisição de equipamentos, entretanto, algumas universidades no país direcionavam o curso ora para as Ciências Humanas, ora para as Ciências Aplicadas. Isso fez com que o ensino do Jornalismo pecasse tanto na parte teórica como no âmbito prático. Pensando em superar essa dicotomia que acompanha o curso de Jornalismo há décadas, as novas Diretrizes Curriculares Nacionais propõem, no que se refere à organização do curso, os seguintes aspectos:

III- promover a integração teoria/prática e a interdisciplinaridade entre os eixos de desenvolvimento curricular; IV- inserir precocemente o aluno em atividades didáticas relevantes para a sua futura vida profissional; $V$ - utilizar diferentes cenários de ensino-aprendizagem permitindo ao aluno conhecer e vivenciar situações variadas em equipes multiprofissionais; VI- propiciar a interação permanente do aluno com fontes, profissionais e públicos do jornalismo desde o início de sua formação, estimulando o aluno a lidar com problemas reais, assumindo responsabilidades crescentes, compatíveis com seu grau de autonomia. (BRASIL, 2013, p. 1)

O novo documento também prevê várias formas de aproximar o ensino à prática do mercado de trabalho. Isso ocorre porque os estudiosos especialistas da área percebem que ambos os aprendizados são essenciais na formação do profissional que atuará como jornalista.

A aplicação das novas diretrizes é uma oportunidade histórica de superar a dicotomia entre teoria e prática em nossos cursos, uma vez que a norma aprovada pela CNE acaba com a ambiguidade entre formar para a prática do Jornalismo e formar para área acadêmica da comunicação, definindo objetivos bem claros e coerentes nesse sentido (SOSTER; TONUS, 2014, p. 10). 
A teoria, no curso de Jornalismo, é a base para que o estudante possa atuar no mercado de forma consciente e humana. A partir dessa teoria, o estudante deverá ser capaz de desenvolver um pensamento crítico em relação aos fatos, distinguir o que é interesse público do interesse do público, questionar, refletir e interagir com a multiplicidade de fontes para que ele possa ajudar a sociedade a compreender humanamente a realidade ao seu redor.

A esmagadora maioria dos professores das cadeiras mais teóricas trabalha de costas para as chamadas disciplinas práticas ou técnicas e os titulares destas não refletem teoricamente a prática. Isso cria nas escolas de Comunicação um abismo profundo, que pode mergulhá-las numa prática pobre ou, na melhor das hipóteses, aquém de suas possibilidades. E este comportamento transfere-se, também, para a relação dos estudantes com os seus laboratórios e oferece um sério risco para a qualidade do processo de ensino-aprendizagem. (SPENTHOF, 1998, p. 164).

Contudo, de nada adianta as novas DCNs para o curso de Jornalismo proporem um equilíbrio entre teoria e prática durante todo o curso, se o Projeto Pedagógico do Curso (PPC) não for eficaz na construção pedagógica dessa relação. Não basta falar aos estudantes que ambas as áreas precisam andar lado a lado, é necessário que eles entendam a relevância desse equilíbrio na realidade, numa bem construída sequência de aprendizado.

Os estudantes precisam desenvolver uma criticidade acerca do fazer jornalístico, tendo em vista que o simples domínio da técnica não elimina as dificuldades advindas da falta da teoria, de leitura crítica.

Embora condição necessária, o domínio de uma técnica não é condição suficiente. Essa forma de encarar o ensino nos cursos profissionalizantes manifesta, de forma muito clara, a ideologia da profissionalização, entendida aqui como uma ideologia de permanência de modelo. (SOSTER; TONUS, 2014, p. 101).

Assim como a desvalorização da parte técnica gera consequências negativas para o curso de Jornalismo, a supervalorização dos laboratórios em detrimento do estudo teórico não é menos perigoso para eficiência do curso (SPENTHOF, 1998). O entusiasmo com as possibilidades do aprender fazendo propiciadas pelos laboratórios não ignora a relevância dos componentes curriculares de cunho científico: "Então, o fato de defender veementemente a existência dos laboratórios, e com qualidade, como defendo, não pode ser confundido com 
desprezo ou descuido em relação à formação humanística/teórica" (SPENTHOF, 1998, p. 165).

Uma boa maneira de unir teoria e prática no curso de Jornalismo é ofertar aos alunos espaços laboratoriais, inclusive em rádio, sob a supervisão de um professor - para que ele oriente como empregar a teoria no fazer jornalístico. "Enquanto há muitas discussões sobre qual seria o melhor caminho para o ensino de Jornalismo no Brasil, o jornal-laboratório tem se mostrado uma maneira simples e eficaz de unir prática e teoria como muitas atividades não fazem" (MARTINS, 2012, p. 93).

\section{A PRÁTICA LABORATORIAL NO ENSINO DE RÁDIO}

A atenção dirigida às atividades laboratoriais pelas novas DCNs para o curso de Jornalismo não diminui com a obrigatoriedade da realização do estágio no decorrer da graduação. "Apesar de enfatizar a realização de duzentas horas de estágio obrigatório, os laboratórios aparecem como um dos pilares do ensino de jornalismo nas DCNs, com alcance transdisciplinar" (PAVAN, 2016, p. 158). Um dos seis eixos de formação, relacionados aos conteúdos curriculares, refere-se justamente à prática laboratorial:

VI - Eixo de prática laboratorial, que tem por objetivo desenvolver conhecimento e habilidades inerentes à profissão a partir da aplicação de informações e valores, integrando os demais eixos, alicerçados em projetos editoriais definidos e orientados a públicos reais, com publicação efetiva e periodicidade regular, tais como: jornal, revista e livro, jornal mural, radiojornal, telejornal, webjornal, agência de notícias, assessoria de imprensa, entre outros. (BRASIL, 2013, p. 5)

São nos laboratórios que os estudantes realmente podem conciliar teoria e prática. Trata-se de espaços onde os alunos têm a oportunidade de ter um contato direto com as fontes (SOSTER; TONUS, 2014), com a pressão do deadline ${ }^{4}$. No âmbito do ensino de Jornalismo, o discente pode desempenhar várias funções, como produção de textos, elaboração de pautas, reportagens, entrevistas e técnicas de locução e edição.

\footnotetext{
${ }^{4}$ No jargão jornalístico, o prazo limite para que uma reportagem ou edição seja concluída.
} 
Eu acho que eles (laboratórios) são o espaço através do qual o ensino de Jornalismo adquire a sua própria vivacidade. Mas nós não podemos manter os órgãos laboratoriais independentes da transmissão de conhecimento, nas disciplinas humanísticas ou nas próprias disciplinas de natureza profissional. Eu só entendo a existência de órgãos laboratoriais, em qualquer curso de Jornalismo, na medida em que eles estejam a serviço da teoria, eles estejam para permitir a aplicação prática de conhecimentos sedimentados e muitas vezes para negar a própria teoria, para produzir um conhecimento novo. Sem essa orientação, parece-me que esses laboratórios podem se tornar verdadeiros equívocos. (MELO apud SOSTER; TONUS, 2014, p. 11).

É imprescindível que os espaços laboratoriais sejam supervisionados por um professor, para que ele possa mediar a conciliação da teoria com a prática. 0 educador deve auxiliar os estudantes no aprofundamento das questões teóricas para, posteriormente, encaminhá-los para a prática nos laboratórios radiofônicos. "Aqui, como em outros momentos, as experiências têm demonstrado que a união entre teoria e prática traz resultados ainda mais satisfatórios" (SANTUARIO, 2006, p. 98).

O autor também ressalta a relevância do papel do professor no sentido de instigar os alunos a desenvolverem nos laboratórios produções criativas, ainda que baseadas em uma reflexão teórica crítica em relação aos produtos radiofônicos já existentes, para que possam contribuir com a transformação e aperfeiçoamento desse modelo de ensino e aprendizado. O espaço acadêmico deve permitir a experimentação com o intuito de incentivar a prática de um fazer jornalístico que fuja dos padrões mercadológicos (SOSTER; TONUS, 2014). As práticas laboratoriais em rádio devem reconhecer a criatividade como parte constituinte da aprendizagem.

Os estudiosos dão enfoque nos laboratórios radiofônicos porque a capacidade de se inserir em novos contextos faz com que a referida mídia seja um espaço de prática e reflexão das teorias do campo jornalístico.

Uma vez entendida e valorizada a sua participação no processo de formação e de desenvolvimento das sociedades, o veículo ganha importância no imaginário dos estudantes e ocupa merecido lugar de análise com interesse e satisfação. As "portas se abrem", assim, nos locais de estudo, para uma reflexão com prática e uma prática reflexiva dos fazeres no rádio. (SANTUARIO, 2006, p. 96).

Outro aspecto importante dos laboratórios é o de que muitos deles permitem aos alunos o contato com temáticas que não estão necessariamente ligadas 
à universidade, mas para situações que os jornalistas profissionais se deparam no dia a dia. Também são relevantes porque nesse ambiente os estudantes têm a oportunidade de veicular uma informação livre de aspectos mercadológicos. Isso corrobora com o que é instituído pelo Código de Ética dos Jornalistas Brasileiros ${ }^{5}$ no artigo 2o do capítulo I - do direito à informação.

Como o acesso à informação de relevante interesse público é um direito fundamental, os jornalistas não podem admitir que ele seja impedido por nenhum tipo de interesse, razão por que:

I- a divulgação da informação precisa e correta é dever dos meios de comunicação e deve ser cumprida independentemente da linha política de seus proprietários e/ou diretores ou da natureza econômica de suas empresas; II- a produção e a divulgação da informação devem se pautar pela veracidade dos fatos e ter por finalidade o interesse público; III- a liberdade de imprensa, direito e pressuposto do exercício do jornalismo, implica compromisso com a responsabilidade social inerente à profissão; IV-a prestação de informações pelas organizações públicas e privadas, incluindo as não governamentais, deve ser considerada uma obrigação social. (CÓDIGO DE ÉTICA, 2007, p. 1).

Por meio da divulgação de suas produções, os estudantes passam a ter responsabilidade por aquilo que é elaborado, assim como o Código de Ética dos Jornalistas Brasileiros também prevê no Capítulo III - Da responsabilidade profissional do jornalista:

Art. 8 O jornalista é responsável por toda a informação que divulga, desde que seu trabalho não tenha sido alterado por terceiros, caso em que a responsabilidade pela alteração será de seu autor [...] Art. 10. A opinião manifestada em meios de informação deve ser exercida com responsabilidade. (CÓDIGO DE ÉTICA, 2007, p. 2)

Desta forma, antes mesmo da formação, os alunos do curso de Jornalismo começam a experimentar o universo prático da profissão. Contudo, para isso, eles precisam estar cientes de seus deveres, que estão explícitos no artigo 12 do Código de Ética dos Jornalistas Brasileiros, no qual se diz que o jornalista deve:

[...] II- buscar provas que fundamentem as informações de interesse público; III- tratar com respeito todas as pessoas mencionadas nas informações que divulgar; IV-informar claramente à sociedade quando suas matérias tiverem

5 Código de Ética dos Jornalistas Brasileiros. 2007. Disponível em: http://fenaj.org.br/wp-content/ uploads/2016/08/codigo_de_etica_dos_jornalistas_brasileiros-1.pdf. Acesso em: 5 set. 2018. 
caráter publicitário ou decorrerem de patrocínios ou promoções; V- rejeitar alterações nas imagens captadas que deturpem a realidade, sempre informando ao público o eventual uso de recursos de fotomontagem, edição de imagem, reconstituição de áudio ou quaisquer outras manipulações [...] VIII- preservar a língua e a cultura do Brasil, respeitando a diversidade e as identidades culturais. (CÓDIGO DE ÉTICA, 2007, p. 3)

Em laboratórios como os de rádio, os estudantes de Jornalismo assumem o compromisso com uma série de funções e produções que levam em conta estas normas, tendo a oportunidade de vivenciar o cotidiano profissional de uma emissora antes de integralizar a formação acadêmica.

\section{CONSIDERAÇÕESSOBREAFORMAÇÃOLABORATORIALRADIOJORNALÍSTICA}

Uma das principais dificuldades que os estudantes enfrentam é conseguir a inserção no mercado de trabalho logo após a formação. Em tempos de crise política, social e econômica, a situação se agrava ainda mais, porque são poucas vagas para uma numerosa formação de novos profissionais ${ }^{6}$. Na disputa por espaço no mercado jornalístico, algumas das principais características exigidas referem-se à experiência e/ou às qualificações. Para um aluno que está prestes a se formar, ou que se formou recentemente, ter um dos dois requisitos exigidos é uma tarefa que exige empenho especial no decorrer do curso.

Uma tentativa de superar esse obstáculo é, durante a graduação, ter passado por estágios no mercado - para muitos, esse seria o passo inicial para uma possível contratação. Contudo inúmeros estudantes nem sequer realizam essa experiência e podem sentir dificuldades em se adaptar à rotina jornalística empresarial. A razão disso é que os profissionais que trabalham com comunicação precisam ter uma elevada capacidade de levantamento de informações e apuração dos fatos para, posteriormente, transformar os dados em produto, num curto período de tempo (SPENTHOF, 1998).

Sendo assim, a passagem por um laboratório, seja ele em rádio, seja em outros campos de formação/atuação profissional jornalística, torna-se essencial para o ingresso no mercado de trabalho, haja vista que a experiência complemen-

6 O Inep indicava que, dos 326 mil matriculados em jornalismo entre 2009 e 2015, apenas 53.500 concluíram a graduação. Fonte: A nova (e incerta) cara do jornalismo. Disponível em: http:// revistapress.com.br/a-nova-e-incerta-cara-do-jornalismo/. Acesso em: 3 fev. 2019. 
ta a teoria estudada. No caso específico dos laboratórios em radiojornalismo, a vivência em uma emissora possibilita a construção de uma perspectiva real do âmbito profissional antes de tomar a direção para os estágios empresariais e institucionais.

O ambiente da rádio permite vivenciar rotinas produtivas bem definidas sob a supervisão de professores ou de profissionais da emissora. Aprendese fazendo. Evidentemente é uma oportunidade que traz ganhos para a formação profissional e antecipa o contato dos alunos com as exigências do mercado. (DEL BIANCO, 2014, p. 158)

Os laboratórios permitem também que os estudantes possam ter contato com um fazer jornalístico que fuja aos padrões mercadológicos. "As estratégias e metodologias aplicadas mobilizam esquemas mentais como análise, crítica, comparação, argumentação, tomada de decisões e classificação de prioridades e relevâncias" (DEL BIANCO, 2014, p. 164).

Isso faz com que os espaços laboratoriais também sejam um ambiente de exercício da ética. O estudante passa a se preocupar com a veracidade do que está divulgando e, caso seja veiculada alguma informação errada, haverá consequências. Antes mesmo da formação, os alunos de jornalismo começam a realizar práticas profissionais orientadas. Um aspecto que justifica a importância dos ambientes laboratoriais, aliás, é o fato de a atividade ser supervisionada por um professor, coisa que geralmente não acontece nos estágios (SPENTHOF, 1998).

Dessa forma, entende-se que os laboratórios radiofônicos contribuem parcialmente para a inserção dos estudantes de Jornalismo no universo profissional: "Um espaço no qual o aluno tem a possibilidade de exercitar a pauta, a redação, a entrevista, a reportagem, a edição e a locução de programas informativos, musicais, culturais e esportivos, atendendo os princípios éticos do jornalismo" (PAVAN, 2016, p. 159). E essa experimentação não contribui apenas para o desenvolvimento do aluno na área do radiojornalismo, uma vez que também estará mais adaptado e reflexivo às rotinas produtivas em seus diferentes cenários midiáticos contemporâneos.

Para que o ensino do radiojornalismo continue a ser significativo na formação acadêmica dos estudantes de comunicação, porém, é preciso que se incorpore nas disciplinas radiofônicas a prática multimídia com o intuito de aprimorar o 
aprendizado. "É necessário aprender as novas formas de interação em um momento em que o rádio se reorganiza, estabelecendo uma espécie de simbiose com as plataformas digitais" (KISCHINHEVSKY, 2014, p. 53-4). Assim, a sintonia com as novas mídias criadas a partir da internet se mostra como uma das mais desafiadoras questões a serem resolvidas nesse universo comunicacional em permanente expansão.

A aprendizagem significativa é a que está diretamente ligada às necessidades imediatas do estudante, ao seu interesse pessoal e profissional (DEL BIANCO, 2014). A autora entende que os estímulos provocados pelo professor-orientador são externos, mas a motivação pela descoberta é interna: "A pessoa torna-se responsável por sua própria aprendizagem. Para jornalistas professores realizar plenamente essa perspectiva de ensinar requer sair da posição de centro do conhecimento para assumir o papel de mediadores" (DEL BIANCO, 2014, p. 174).

A produção laboratorial dirigida a públicos externos no curso de Jornalismo gera modificações no processo de ensino-aprendizagem, além de complexificar as relações entre professor e alunos, ao exigir critérios éticos que extrapolam os significados das atividades avaliativas realizadas em sala de aula, "perdendo assim o caráter de exercício formal, mero requisito para obtenção de grau e aprovação numa disciplina de graduação" (KISCHINHEVSKY, 2014, p. 59). Diante das perspectivas apresentadas, o espaço pedagógico necessita de recorrentes reflexões sobre sua inserção no ensino de Jornalismo, para a formação de um profissional crítico e capaz de intervir afirmativamente num mercado de trabalho em constante transformação.

Por fim, apesar do caráter preponderantemente técnico-prático, os laboratórios acadêmicos orientados se mostram capazes de romper conhecidas comparações dicotômicas com relação ao ensino de áreas do conhecimento como a Sociologia, a Antropologia, a Filosofia, a Política e a Economia, entre outras tantas que tomam como objeto a realidade social cotidiana e interferem diretamente na perspectiva profissional. Um oportuno momento da graduação para aproximar metodologias pedagógicas no processo formativo e de efetivo tensionamento da produção experimental com os paradigmas teóricos que constituem o campo de estudo do Jornalismo. 
Uma reflexão acerca da formação laboratorial em rádio e a perspectiva das novas DCNs para o curso de Jornalismo

\section{REFERÊNCIAS}

BRASIL. Diretrizes Curriculares Nacionais para o curso de Jornalismo. Brasília: CNE/MEC 2013. Disponível em: http://portal.mec.gov.br/dmdocuments/documento_final_cursos_ jornalismo.pdf. Acesso em: 30 ago. 2018.

CAMPELO, Wanir. Radioescola ponto com: uma opção educomunicativa. In: SOSTER, Demétrio de Azeredo; TONUS, Mirna (Org.). Jornalismo-laboratório: rádio. Santa Cruz do Sul, RS: Edunisc, 2014. p. 63-76.

DEL BIANCO, Nélia. Quando a sala de aula é um laboratório de ensino-aprendizagem de radiojornalismo. In: SOSTER, Demétrio de Azeredo; TONUS, Mirna (Org.). Jornalismolaboratório: rádio. Santa Cruz do Sul, RS: Edunisc, 2014. p. 158-75.

FEDERAÇÃO NACIONAL DOS JORNALISTAS (FENAJ). Primeiro curso de Jornalismo do Brasil completa 70 anos. Brasília, 17 maio 2017. Disponível em: http://fenaj.org.br/primeirocurso-de-jornalismo-do-brasil-completa-70-anos/. Acesso em: 16 nov. 2018.

KISCHINHEVSKY, Marcelo. Radiojornalismo para emissoras comunitárias e educativas: uma experiência de ensino-aprendizagem no AudioLab FCS/UERJ. In: SOSTER, Demétrio de Azeredo; TONUS, Mirna (Org.). Jornalismo - laboratório: rádio. Santa Cruz do Sul, RS: Edunisc, 2014. p. 49-62.

MARTINS, Rafael Barbosa Fialho. O jornal-laboratório como exercício da prática e teoria na formação superior em Jornalismo. Revista de Ciências Humanas, Viçosa, MG, v. 12, n. 1, p. 84-94. jan./jun. 2012.

MEDITSCH, Eduardo. O ensino do radiojornalismo em tempos de internet. In: CONGRESSO NACIONAL DE COMUNICAÇÃO - INTERCOM (GT Rádio e Mídia Sonora), 24., set. 2001, Campo Grande, MS. Anais [...]. Campo Grande, MS, 2001. p. 1-10. Disponível em: http:// www.intercom.org.br/papers/nacionais/2001/papers/NP6MEDITSCH.pdf. Acesso em: 26 nov. 2019.

PAVAN, Ricardo. O ensino laboratorial de rádio no Curso de Jornalismo da UFG: do espaço pedagógico à formação profissionalizante. In: MORAES, Ângela Teixeira de; MAIA, Juarez Ferraz de; FARIAS, Salvio Juliano Peixoto (Org.). Estudos contemporâneos em Jornalismo. Goiânia: UFG, 2016. p. 157-73. (Coletânea 4).

SANTUARIO, Marcos. Edição em rádio: ensinar é preciso, escolher não é preciso. In: FELIPPI, Ângela; SOSTER, Demétrio de Azeredo; PICCININ, Fabiana (Org.). Edição em Jornalismo: ensino, teoria e prática. Santa Cruz do Sul, RS: Edunisc, 2006. p. 96-105. 
SOSTER, Demétrio de Azeredo; TONUS, Mirna (Org.). Jornalismo-laboratório: rádio. Santa Cruz do Sul, RS: Edunisc, 2014.

SPENTHOF, Edson Luiz. A experiência laboratorial na Rádio Universitária da UFG e o debate sobre o aperfeiçoamento pedagógico dos cursos de jornalismo. In: FÓRUM NACIONAL DE PROFESSORES DE JORNALISMO, 8., 2005, São Bernardo do Campo, SP. Anais [...]. São Bernardo do Campo, SP, 2005. p. 1-13.

SPENTHOF, Edson Luiz. A importância das rádios e TVs universitárias como laboratórios. Revista Comunicação \& Informação, Goiânia, v. 1, n. 1, p. 153-66, jan./ jun. 1998.

\section{Sobre os autores:}

Ricardo Pavan: Doutor e mestre em Comunicação pela Universidade do Vale do Rio dos Sinos (Unisinos-RS). Pesquisador na Linha de Pesquisa Mídia e Cultura do Programa de Pós-Graduação em Comunicação e professor do Curso de Jornalismo da Universidade Federal de Goiás (UFG). E-mail: pavan.ufg@gmail.com, Orcid: http://orcid.org/0000-0001-6226-1562

Gabriela Starneck Lopes de Araújo: Jornalista com experiência em Rádio e TV. E-mail: pavanferdinando0@gmail.com, Orcid: http://orcid.org/0000-0002-7282-6309

Recebido em 27 de fevereiro de 2019

Aprovado em 29 de julho de 2019 